\title{
The Effects of Herobic Training on Serum Level of Liver Enzymes and Metabolic Syndrome Risk Factors in Young Inactive Women
}

\author{
Fatemeh Islami (Msc) \\ Department of physical education, \\ Faculty member of Golestan \\ University, Gorgan, Iran \\ Corresponding Author: Fatemeh Islami \\ Email: f.eslami@gu.ac.ir
}

Tel: 09111789931

Address: Golestan University, Gorgan, Iran

Received : 28 Sep 2015

Revised: 01 Oct 2015

Accepted: 27 Oct 2015

\section{ABSTRACT}

Background and Objectives: Nonalcoholic fatty liver disease is the most common chronic liver disorder and is also currently considered as the hepatic manifestation of metabolic syndrome. Regular exercise training may decrease fatty liver disease complications, although its impact is not yet clear. This study aimed to evaluate the effects of six weeks of aerobic training on liver enzymes and other factors contributing to metabolic syndrome in young inactive women.

Methods: In this quasi-experimental study, 37 inactive overweight women were randomly divided into an experimental and a control group. The experimental one participated in a controlled aerobic training program (5-minute interval walking) at $65-90 \%$ maximum heart rate for 6 weeks, $45-90$ minutes per session and 4 sessions per week. Blood samples were taken following 12 hours of fasting, both before and after the training program.

Results: The levels of aspartate aminotransferase and alkaline phosphatase decreased in both groups. Alanine aminotransferase level, weight and waist circumference were significantly decreased in the experimental group following the 6-week exercise training $(\mathrm{P}<0.05)$. High-density lipoprotein concentration was significantly increased in both groups. Gamma-glutamyl transferase level was decreased in the experimental group, but increased in the control group. The results showed no significant difference in the basic profile of participants, liver enzymes concentration and lipid profile between the experimental and control group.

Conclusion: Six weeks of aerobic training may help prevent hepatic damage through decreasing serum levels of liver enzymes, anthropometric factors and some metabolic syndrome factors associated with nonalcoholic fatty liver disease.

Keywords: Fatty liver, Aerobic training, Metabolic syndrome, Liver enzyme. 


\section{INTRODUCTION}

Metabolic syndrome refers to a set of risk factors that increase the risk of cardiovascular disease, type 2 diabetes and chronic kidney disease $(1,2)$. According to the American Heart Association and the National Heart, Lung, and Blood Institute reports in 2005, metabolic syndrome is defined based on the existence of three or more of the following indications: (1) abdominal obesity (waist circumference greater than $88 \mathrm{~cm}$ in women and $102 \mathrm{~cm}$ in men); (2) increased blood triglycerides (TGs) (more than $150 \mathrm{mg} / \mathrm{dl}$ ); (3) decreased High-Density LipoproteinCholesterol (HDL-C) concentration (less than $40 \mathrm{mg} / \mathrm{dl}$ in men and $50 \mathrm{mg} / \mathrm{dl}$ in women); (4) increased blood pressure $(>130 \mathrm{mmHg}$ systolic and $>85 \mathrm{mmHg}$ diastolic or hypertension medication); and fasting blood glucose disorder or diabetes medication (3). It is demonstrated that most of the above indications are accompanied by nonalcoholic fatty liver disease (NAFLD) (4), the most common chronic liver disorder (5). Currently, NAFLD is often regarded as the hepatic manifestation of metabolic syndrome(6). While the prevalence of NAFLD is estimated to be about $14-34 \%$ in Europe, Asia and America over the past few years $(7,8)$, it affects $3-24 \%$ of the Iranian population(9). Recent studies have shown the association of NAFLD with metabolic syndrome, obesity, physical inactivity and elevation of other risk factors [ body mass index (BMI), Waist-to-hip ratio, alanine aminotransferase (ALT) concentration, aspartate aminotransferase (AST), lipid, lipoprotein] (10,11). AST, ALT, alkaline phosphatase (ALP), and Gamma-glutamyl transferase (GGT) are among the most commonly used enzymes to indicate liver damage $(12,13)$. Although high plasma levels of liver enzymes such as ALP, ALT and AST are associated with NAFLD, metabolic syndrome, fatty liver and increased liver enzyme activity even at normal concentrations may predict these diseases (14-16). Nikroo et al studied the effect of diet and aerobic training on serum ALT levels in NAFLD patients. The participants performed aerobic training (walking, jogging and running) at 55$60 \%$ heart rate reserve for eight weeks and three sessions per week. The result of the mentioned study showed significant serum ALT level changes within the group of patients under aerobic training with diet and no significant difference in serum aminotransferase levels between the test groups (17). According to Bashiri et al., the type, duration and intensity of exercise training may affect liver enzyme activity (18). Thus, liver cell membranes are likely to be damaged in endurance exercises $(19,20)$. Although endurance and resistance training may lead to increased liver enzyme level and liver damage $(21,22)$, interval aerobic training is considered as a preventive approach to reduce the risk of NAFLD by decreasing body weight, cholesterol, blood TGs and liver enzymes particularly ALT and AST $(23,24)$. Walking is considered an appropriate activity, as it can be practiced by a large number of people, with no additional cost and low risk of injury $(25,26)$. In this study, a specific type of aerobic training was designed to be applicable to inactive and overweight people, in the form of 5-minute interval walking. This study aimed to investigate the impact of the 5-minute interval walking on the NAFLD predicting factors and some factors associated with metabolic syndrome. This may help develop appropriate training protocols for people at risk.

\section{MATERIAL AND METHODS}

The study population consisted of female students aged 20-28 years, studying at the Golestan University, Iran. A quasiexperimental method with pre- and post-test approach was implemented, as well as a training and a control group. After obtaining the required permits from the University and ethical approval for this research project, 37 inactive and overweight $(25 \leq \mathrm{BMI} \leq 29.9)$ volunteers were participated in this study. The participants were then randomly assigned into a training $(n=18)$ and a control group $(n=19)$ (Table 1). Liver enzymes and lipid profiles were measured via enzymatic method using Pars Azmoon Kit. The aerobic training protocol consisted of 6- week aerobic training with 4 sessions per week. The subjects performed training at $65-75 \%$ maximum heart rate (MHR) with one repetition for 45 minutes in the first week; $65-75 \%$ MHR with two repetitions for 90 minutes in the second week; $75-85 \%$ MHR with one repetition for 45 minutes in the third week; $75-85 \%$ MHR with two repetitions for 90 minutes the fourth week; $85-95 \%$ MHR with one repetition for 45 minutes in the fifth week; and $85-95 \%$ MHR 
with two repetitions for 90 minutes in the sixth week. In order to adjust the training load, the number of repetitions and training intensity were increased every alternate week so that aerobic training intensity was increased by $10 \%$ fortnightly. Aerobic training consisted of 5-minute warm-up including walking, gentleto-quick stretching, static and dynamic stretching, 35-70 minutes of main exercises including 5-minute interval walking with 2 minute rest intervals, and 5 minutes of cooldown exercises including walking as well as static and dynamic stretching exercises while sitting and lying on the back (27). The participants were instructed on how to control their heart rate, count and perform walking exercises three days before the start of the training protocol. In every training session, the trainees performed the initial warm-up followed by 5 -minute walking. Then, they did 2 minutes of active rest by gentle walking and simple exercises. In the same manner, they did 5 bouts of 5 -minute walking training. The participants took 5 minutes of inactive rest between the bouts in the session when they repeated 5 bouts of 5 -minute training twice. They took 5 minutes of inactive rest between the two sets. MHR was measured using the following equation: $\mathrm{MHR}=206-(0.88 \times$ xage $)$, in order to adjust the training intensity and whiletraining heart rate (28). MHR was calculated for all participants and then they were instructed to do training at their 65-95\% MHR. The control group, however, were asked not to do any exercise training during the training program. The data were analyzed using SPSS (version 19) software. The obtained data were described using mean and standard deviation. Kolmogorov-Smirnov and Levene's tests were performed to examine the normality of data and homogeneity of variances, respectively. Paired and independent t-tests were used for within-group and between-group comparisons, respectively. The level of statistical significance was set at $\mathrm{P} \leq 0.05$. The exclusion criteria were as follows: pregnancy, breast feeding, professional exercise training, smoking, alcohol and drug abuse, acute or chronic liver disease (i.e. fatty liver, viral hepatitis and cirrhosis), taking any medication for more than two weeks just prior to or within three months before the study (e.g. hormonal, antidepressant and antipsychotic medicines), a weight gain/loss diet within three months prior to the study, any endocrine disorder affecting the weight (e.g. Cushing's syndrome, thyroid disorders, diabetes, congenital adrenal hyperplasia, renal and cardiac diseases), a history of abdominal surgery, drug-induced fatty liver due to medications such as corticosteroids, androgens, synthetic estrogens, Tamoxifen and vitamin A. The subjects were thoroughly examined by a physician and then informed of the research conditions. After obtaining written informed consent from all the participants and before the start of the study, anthropometric indices such as height, weight, waist and hip circumferences of the subjects were measured. To this end, weight at fasting was measured with the subjects wearing the least possible clothing and no shoes, using a Secaanalog scale with an accuracy of $500 \mathrm{~g}$. The subjects' height was measured barefoot in the standing upright position with their heel and calf tangent to the wall, using a Seca wall-mounted stadiometer with an accuracy of $0.5 \mathrm{~cm}$. BMI was measured using the following equation: weight $(\mathrm{kg}) / \mathrm{squared}$ height $\left(\mathrm{m}^{2}\right)$. Waist circumference was measured at the narrowest abdominal section between the last rib and the iliac bone with the subjects at an upright posture with relaxed abdominal muscles, using a tape measure. Hip circumference was measured at the largest hip area. Waist-to-hip ratio (WHR) was measured by dividing waist circumference to hip circumference. The subjects were instructed to avoid exercise training within 24 hours prior to blood sampling and to have a small meal at the previous night. Blood samples were taken following 12-14 hours of fasting both before the start of the training protocol and 48 hours after the last training session. Both the control and training groups attended the examiner at Dr. Balkhi Pathological Laboratory at 7:30 A.M. Blood samples were obtained $(10 \mathrm{ml})$ and then the samples were centrifuged at 1500-2000 rpm for 10 minutes to separate serum and measure blood parameters.

Table 1- Demographic characteristics of subjects. Subject of the two test groups were similar in terms of age, height, weight and BMI $(\mathrm{P}>0.05)$.

\begin{tabular}{cccccc}
\hline Group & Number & Age $(\mathrm{yr})$ & Height $(\mathrm{cm})$ & Weight $(\mathrm{kg})$ & BMI $\left(\mathrm{kg} / \mathrm{m}^{2}\right)$ \\
\hline Training & 18 & $22.42 \pm 2.16$ & $160 \pm 5.58$ & $71.25 \pm 7.93$ & $28.28 \pm 3.76$ \\
Control & 19 & $21.94 \pm 1.39$ & $\mathbf{1 6 1 . 7 8} \pm 7.08$ & $\mathbf{7 2 . 6 5} \pm 11.58$ & $27.71 \pm 3.65$ \\
Total & 37 & $22.18 \pm 1.81$ & $160.89 \pm 6.35$ & $71.95 \pm 9.81$ & $28.00 \pm 3.16$ \\
\hline
\end{tabular}


Table 2- Mean and standard deviation of the research variables before and after 6 weeks of aerobic training

\begin{tabular}{|c|c|c|c|c|c|}
\hline Variables & Groups & Before training & After training & $\begin{array}{c}\text { Sig. } \\
\text { (dependent } t)\end{array}$ & $\begin{array}{c}\text { Sig. } \\
\text { (independent } t \text { ) }\end{array}$ \\
\hline Weight (kg) & $\begin{array}{c}\text { Control } \\
\text { Training }\end{array}$ & $\begin{array}{c}72.65 \pm 11.58 \\
71.25 \pm 7.93\end{array}$ & $\begin{array}{c}72.35 \pm 11.89 \\
70.43 \pm 8.02\end{array}$ & $\begin{array}{c}0.488 \\
0.006 *\end{array}$ & 0.319 \\
\hline BMI $\left(\mathrm{kg} / \mathrm{m}^{2}\right)$ & $\begin{array}{c}\text { Control } \\
\text { Training }\end{array}$ & $\begin{array}{l}27.71 \pm 3.65 \\
28.28 \pm 3.76\end{array}$ & $\begin{array}{l}27.61 \pm 3.88 \\
27.52 \pm 2.92\end{array}$ & $\begin{array}{l}0.516 \\
0.116\end{array}$ & 0.182 \\
\hline & Control & $95.10 \pm 9.04$ & $94.26 \pm 8.81$ & 0.053 & 0.605 \\
\hline $\begin{array}{l}\text { Waist(cm) } \\
\text { Hip (cm) }\end{array}$ & $\begin{array}{c}\text { Training } \\
\text { Control }\end{array}$ & $\begin{array}{c}94.78 \pm 6.89 \\
107.05 \pm 6.72\end{array}$ & $\begin{array}{c}94.21 \pm 6.59 \\
106.94 \pm 6.94\end{array}$ & $\begin{array}{l}0.069 \\
0.761\end{array}$ & 0.142 \\
\hline WHR (Ratio) & $\begin{array}{c}\text { Training } \\
\text { Control }\end{array}$ & $\begin{array}{c}105.47 \pm 5.64 \\
0.88 \pm 0.05\end{array}$ & $\begin{array}{c}104.68 \pm 5.45 \\
0.88 \pm 0.05\end{array}$ & $\begin{array}{l}0.018 * \\
0.031^{*}\end{array}$ & 0.066 \\
\hline TG (mg/dL) & $\begin{array}{c}\text { Training } \\
\text { Control }\end{array}$ & $\begin{array}{c}0.89 \pm 0.05 \\
75.10 \pm 23.86\end{array}$ & $\begin{array}{c}0.89 \pm 0.04 \\
70.63 \pm 27.64\end{array}$ & $\begin{array}{l}0.660 \\
0.145\end{array}$ & 0.345 \\
\hline HDL-C(mg/dL) & $\begin{array}{c}\text { Training } \\
\text { Control }\end{array}$ & $\begin{array}{l}84.94 \pm 53.35 \\
39.10 \pm 11.32\end{array}$ & $\begin{array}{c}89.52 \pm 45.74 \\
48.78 \pm 9.99\end{array}$ & $\begin{array}{c}0.617 \\
0.001 *\end{array}$ & 0.177 \\
\hline $\operatorname{AST}(\mathbf{U} / \mathbf{L})$ & $\begin{array}{c}\text { Training } \\
\text { Control } \\
\text { Training }\end{array}$ & $\begin{array}{c}36.15 \pm 11.03 \\
24.05 \pm 3.80 \\
23.89 \pm 6.39\end{array}$ & $\begin{array}{r}50.57 \pm 8.26 \\
18.10 \pm 7.15 \\
16.84 \pm 5.60\end{array}$ & $\begin{array}{l}0.000 * \\
0.000 * \\
0.000 *\end{array}$ & 0.579 \\
\hline $\operatorname{ALT}(\mathbf{U} / \mathbf{L})$ & Control & $20.21 \pm 16.35$ & $17.47 \pm 15.01$ & 0.560 & 0.679 \\
\hline AST/ALT(Ratio) & $\begin{array}{c}\text { Training } \\
\text { Control } \\
\text { Training }\end{array}$ & $\begin{array}{c}17.84 \pm 12.55 \\
1.55 \pm 0.64 \\
1.62 \pm 0.61\end{array}$ & $\begin{array}{c}12.94 \pm 7.64 \\
1.46 \pm 0.59 \\
1.51 \pm 0.51\end{array}$ & $\begin{array}{c}0.049 * \\
0.544 \\
0.294\end{array}$ & 0.895 \\
\hline $\operatorname{ALP}(\mathbf{U} / \mathbf{L})$ & $\begin{array}{c}\text { Control } \\
\text { Training }\end{array}$ & $\begin{array}{l}206.89 \pm 79.16 \\
202.42 \pm 72.70\end{array}$ & $\begin{array}{l}179.52 \pm 51.01 \\
170.15 \pm 65.47\end{array}$ & $\begin{array}{l}\text { 0.004* } \\
0.000 *\end{array}$ & 0.651 \\
\hline GGT(U/L) & $\begin{array}{c}\text { Control } \\
\text { Training }\end{array}$ & $\begin{array}{l}12.31 \pm 6.60 \\
16.05 \pm 8.68\end{array}$ & $\begin{array}{c}13.52 \pm 11.49 \\
15.47 \pm 8.22\end{array}$ & $\begin{array}{l}0.424 \\
0.681\end{array}$ & 0.383 \\
\hline
\end{tabular}

* Statistical significance( $(\mathbf{P} \leq \mathbf{0 . 0 5})$

\section{RESULTS}

The results showed no significant difference in weight, age, height and BMI between the control and experimental participants $(\mathrm{P}>0.05)$ (Table1). ALP, ALT and AST concentrations as well as weight and waist circumference significantly decreased in the training group following 6 weeks of exercise training $(\mathrm{P}<0.05)$. However, there was no significant difference between the groups regarding these variables. HDL-C concentration significantly increased in the training group following the 6-week exercise training, while no significant difference was observed between the control and training group. AST, ALT and GGT serum levels as well as hip circumference and BMI were decreased, but TGs increased in the training cases following the six weeks of exercise training $(\mathrm{P}>0.05)$. However, the results revealed no significant difference between the two groups regarding these variables. Unlike the control subjects $(\mathrm{P}<0.05)$, WHR value did not change in the experimental participants following the six weeks of aerobic training. Moreover, there was no significant difference in WHR between the two tested groups (Table2).

\section{DISCUSSION}

The findings showed that six weeks of aerobic training (5-minute interval training) decreased serum levels of liver enzymes, weight and BMI and improved the risk factors of metabolic syndrome (increased HDL-C level). Several studies have reported a decreased liver enzyme level following various aerobic activities (2932). Consistent with our findings, Farzanegi et al reported that 6 weeks of aerobic training decreased ALT, AST and ALP enzymes but did not affect lipid levels (33).Davoodi et al. also observed that eight weeks of aerobic training at $50-70 \%$ VO2max could significantly decrease the serum levels of ALT and AST in male patients with fatty liver disease (5). Abd El- Kader et al. claimed that aerobic training significantly decreased ALT, ALP, AST and GGT concentrations, in agreement with the results of the present study (34). The decreased weight and liver enzyme levels following the 6 weeks of aerobic training in this study may be related to increased consumption of these enzymes, elimination of their secretion-inducing factors or weight loss. In addition to the positive adjustment of antioxidant defense, aerobic training may induce greater decrease in ALT 
and AST levels by decreasing oxidative stress and inflammation $(24,35)$. In the present study, it is likely that rest-intervals between training bouts helped reduce liver stress in young women. According to Hany, 12 weeks of aerobic training without energy restriction reduces liver enzymes. Regular exercise training decreases the enzymes transferringamino acids, which in turn decreases protein decomposition and helps preserve body fat mass (36). Contrary to our findings, Khorshidi et al., reported that 10 weeks of aerobic training exerted no significant effect on ALP serum concentrations (37). Devries et al showed that endurance training for 12 weeks did not induce a significant change in ALT levels (38). Moreover, the results of a study on the effect of swimming training on liver enzymes in young women, who underwent the training protocol at $65-85 \%$ MHR for 8 weeks, 3 sessions per week, and 60-90 minutes per session, showed no significant change in AST and ALT levels (39). Skenderi et al found that liver and muscular injuries following $246 \mathrm{~km}$ continuous running led to increased serum ALT and AST (40). Although it is expected that regular exercise training should decrease liver enzymes, Tartibian et al., reported significant increase in ALP following 9 weeks of aerobic training (41). Barzegarzadeh and Dabidy-Roshan also reported a significant increase in ALP, ALT and AST concentrations in female rats following 6 and 12 weeks of continuous and interval training on treadmill (42). These findings' inconsistencies may be due to differences in individual characteristics such as subjects' age, physical fitness and higher baseline of normal levels for ALP, AST, GGT and ALT enzymes in the subjects. In other words, the type of sport activities exerts variable effects on secretory and metabolic systems, which may account for the inconsistency between the present and previous findings. Environmental factors such as climate, weather, temporal and spatial conditions of the training venue, as well as environmental stimuli such as stress and excitations may also affect the results. Consistent with the results of this study, a review study cited a decrease in AST/ALT ratio compared with the baseline levels, following 3 months of aerobic training (43). Still, a study has shown that resistance and aerobic training does not induce a significant change in AST/ALT ratio (43). Another study showed that muscular training lead to increased AST/ALT ratio (44), which is inconsistent with our findings. The inconsistency in these findings may be associated with different exercise intensity, type and duration, as well as the subjects' health condition. Apparently, TG concentration slightly increased in the training group while it slightly decreased in the control group. Bizheh et al. reported that BMI and TG significantly decreased in the experimental subjects following three months of aerobic training at $75-85 \%$ MHR (45). Variations in the TG level may be associated with (lipoprotein lipase) LPL response to exercise training. LPL is one of the enzymes, adjusting lipoproteins and decomposing TGs in triglyceride-rich lipoproteins. On the other hand, studies suggest that the decreased hepatic lipase is inhibited following regular aerobic training. Thus, the generation of VLDL and LDL triglycerides is decreased. In this study, HDL-C concentration was significantly increased in both groups. A complex mechanism is involved in HDL-C increase following exercise training. Enzymes such as LPL, HL and CEPT play an important role in HDL-C concentration alterations. Plasma is the main cause of variations in HDL$\mathrm{C}$ concentration through hydrolysis of TGs. Increased HDL-C concentration following exercise training may be related to decreased CETP concentration or activity. CEPT is responsible to carry lipids in HDL-C molecule and other lipoproteins and is reported to decrease following exercise training. Decreased CEPT allows slowed down HDL-C catabolism (increased half-life), which results in increased HDL-C concentration (46). Increased HDL-C concentration reduces the risk of NAFLD and metabolic syndrome. Lifestyle modification coupled with weight loss and exercise training may be considered as the basic treatments. It is reported that regular exercise training provides a shield against liver injuries, inflammation, and hepatic fibrosis through suppression of macrophages filtration (33). Studies have shown that 6 weeks of aerobic training leads to a significant decrease in BMI of the experimental subjects, with no significant change in lipid profile between the experimental and control groups. Consistent with the mentioned findings, the results of this study showed a greater decrease in BMI and weight in the experimental subjects compared 
with the controls, following the 6 weeks of exercise training (33). In a study on obese adolescents with NAFLD and their comparison with healthy obese adolescents, equal levels of serum TGs and free fatty acids were reported in both groups while lower HDL-C concentration was observed in the obese adolescents with NAFLD (47). The results of this study represented that weight $(\mathrm{P}<0.05)$, waist circumference, and hip circumference $(\mathrm{P}<0.05)$ decrease in both the control and experimental groups following 6 weeks of aerobic training with no change observed in WHR. Meanwhile, Cox et al reported that a significant change might not be observed in the body composition by solely relying on physical exercise without a diet (48). However, shortterm aerobic training (interval walking) effectively contributed to weight loss in overweight women in the present research. The findings of $\mathrm{Bi}$ et al. study, suggested that BMI, waist-to-hip ratio, serum total triglycerides, serum total cholesterol, ALT, AST, and GGT values are all higher in the NAFLD group than in the control group. For moderate and severe NAFLD patients, the ALT, AST and GGT values were significantly increased, high density lipoprotein cholesterol was decreased,

\section{REFERENCES}

1. Reynolds K, He J. Epidemiology of the metabolic syndrome. Am J Med Sci 2005; 330(6): 273-9.

2. Grundy SM. Metabolic syndrome scientific statement by the American Heart Association and the National Heart, Lung, and Blood Institute. ArteriosclerThrombVascBiol 2005; 25(11): 2243-4.

3. Grundy SM, Cleeman JI, Daniels SR, Donato KA, Eckel RH, Franklin BA, et al. Diagnosis and management of the metabolic syndrome: an American Heart Association/National Heart, Lung, and Blood Institute Scientific Statement. Circulation 2005; 112(17): 2735-52.

4. Jamali R, Jamali A. Fatty Liver Disease. $1^{\text {st }}$ ed. Kashan: Davat; 2010. P. 9-10. [Persian]

5. Davoodi M, Moosavi H, Nikbakht M. The effect of eight weeks selected aerobic exercise on liver parenchyma and liver enzymes (AST, ALT) of fat liver patients. Journal of Shahrekord University of Medical Sciences. 2012; 14(1): 84-90. [Persian]

6. Fahimi F, Shafiee K, Ahmadi J, Mehrabian M, Pezeshki E, A. Dehgani.Relationship Between Nonalcoholic Fatty Liver Disease with Hemodynamic Indexes of Intracranial Cerebral Vessels in Tran cranial Doppler Ultrasound. J RafsanjanUniv Med Sci 2012; 11(6): 567-74. [Persian]

7. Armsrong M J, Houlihan D D, Bentham L, Shaw J C, Cramb R, Olliff $\mathrm{S}$, et al. Presence and severity of nonalcoholic fatty liver disease in a large prospective primary care cohort. J Hepatol. 2012. 56 (1): 234-40. and drinking much, heavy entertainment and less exercise were more prevalent $(\mathrm{P}<0.001)$. There was strong correlation between serum liver enzyme levels and NAFLD $(\mathrm{P}<0.001)$, with GGT being a more sensitive marker for NAFLD than ALT or AST. ALT and GGT were independent predictors for NAFLD, and GGT was a better predictor than ALT for NAFLD $(48,49)$.

\section{CONCLUSION}

Based on the results of this study, 6 weeks of aerobic training (with rest intervals between training bouts) may prevent liver injury by decreasing serum level of liver enzymes, anthropometric variables and some NAFLDrelated metabolic syndrome factors. Nevertheless, more studies are required to further evaluate the effects of aerobic training on liver diseases in obese women.

\section{ACKNOWLEDGEMENT}

We would like to thank all people who cooperated with us in this research, particularly the students in

Golestan University and the staff of Dr. Balkhi laboratory.

\section{CONFLICT OF INTEREST}

Therer are no conflicts of interest.

8. Caballeria L, Auladell M A, Torán P, Miranda D, Aznar J Pera G, et al. Prevalence and factors associated with the presence of non-alcoholic fatty liver disease in an apparently healthy adult population in primary care units. BMC Gastroenterol. 2007. 7(41):1-6.

9. Khedmat $\mathrm{H}$, Fallahian $\mathrm{F}$, Abolghasemi $\mathrm{H}$, Hajibeigi B, Attarchi Z, Alaeddini F, Holisaz M T, Pourali M, Sharifi S, Zarei N. Serum gammaglutamyltransferase, alanine aminotransferase, and aspartate aminotransferase activity in Iranian healthy blood donor men. World J Gastroenterol 2007; 13: 889-894.

10. Timothy S. Church, Jennifer 1. Kuk, Robert Ross, elisa 1. Priest, Emily biltoff, and Steven n. Blair.Association of Cardiorespiratory Fitness, Body Mass Index, andwaist Circumference to Nonalcoholic Fatty Liver Disease.GASTROENTEROLOGY;2006; 130:2023-2030.

11. Wilkins T, Tadkod A, Hepburn I, Schade RR. Nonalcoholic fatty liver disease: diagnosis and management. Am Fam Physician 2013; 88(1): 3542.

12. Vozarova B, Stefan N, Lindsay RS, Saremi A, Pratley RE, Bogardus $\mathrm{C}$, et al. High alanine aminotransferase is associated with decreased hepatic insulin sensitivity and predicts the development of type 2 diabetes. Diabetes. 2002 Jun; 51(6): 1889-95. 
13. Larson-Meyer DE, Newcomer BR, Heilbronn LK, Volaufova J, Smith SR, Alfonso AJ, et al. Effect of 6month calorie restriction and exercise on serum and liver lipids and markers of liver function. Obesity (Silver Spring). 2008; 16(6): 1355-62.

14. Khodarahmi R, Bahrami N. Metabolism. 1st ed.Tehran: NoreDdanesh Pub; 2003.[Persian]

15. Nannipieri M, Gonzales C, Baldi S, Posadas R, Williams K, Haffner SM, et al. Liver enzymes, the metabolic syndrome, and incident diabetes. Diabetes Care. 2005; 28(7): 1757-62.

16. Chen ZW, Chen LY, Dai HL, Chen JH, Fang LZ. Relationship between alanine aminotransferas levels and metabolic syndrome in nonalcoholic fatty liver disease.J Zhejiang Univ Sci. 2008; 9:8:616-622.

17. Nikroo H, Nematy M, Sima HR, Attarzade Hosseini SR. The effect of restricted diet with or without aerobic training program on cardio respiratory fitness and anthropometric indices in patients with non alcoholic steatohepatitis. Journal of North Khorasan University of Medical Sciences; 2011; 3(3); 91-9. [Persian]

18. Bashiri J, Gaeini AA, Nikbakht H. Simultaneous Effect of talking creatine monohydrate and resistant practice on serum live enzyme activity of athletic men. Iranian Journal of Endocrinology and Metabolism. 2009; 12:1:42-47. [Persian]

19. Rahnama N, Nouri R. Exercise Biochemistry. Tehran: Samt Press; 2009. [Persian]

20. Rawson ES, Persky AM. Mechanisms of muscular adaptations to creatine supplementation. International Sport Medical Journal. 2007; 8:43-53.

21. Fallah Azad V, Zeydi M. Comprehensive information on diagnostic tests. 3rd ed. Tehran: Shabak Press; 2009. [Persian]

22. Saadati H, Valadbeigi M. Comprehensive guide of Laboratory Test interpration. Shiraz: Enteshar Press; 2010. [Persian]

23. Lawlor DA, Sattar N, Smith GD, Ebrahim SH. The associations of physical activity and adiposity with alanine aminotransferase and gammaglutamyltransferase. Am J Epidemiol. 2005; 161(11): 1081-8.

24. Guo R, Liong EC, So KF, Fung ML, Tipoe GL. Beneficial mechanisms of aerobic exercise on hepatic lipid metabolism in non-alcoholic fatty liver disease.Hepatobiliary Pancreat Dis Int. 2015 Apr; 14(2):139-44.

25. Haram PM, Kemi OJ, Lee SJ, Bendheim MØ, AlShare QY, Waldum HL, Gilligan LJ, Koch LG, Britton SL, Najjar SM, WisløffU.Aerobic interval training vs. continuous moderate exercise in themetabolic syndrome of rats artificially selected for low aerobic capacity. Cardiovasc Res. 2009 Mar 1;81(4):723-32.

26. Montesi L, Moscatiello S, Malavolti M, Marzocchi R, Marchesini G. Physical activity for the prevention and treatment of metabolic disorders. Intern Emerg Med. 2013 Dec; 8(8):655-669.

27. Johnson NA, George J. Fitness versus fatness: moving beyond weight loss in nonalcoholic fatty liver disease. Hepatology. 2010; 52(1): 370-381.
28. Gulati M, Shaw LJ, Thisted RA, Black HR, BaireyMerz CN, Arnsdorf MF. Heart rate response to exercise stress testing in asymptomatic women: the st. James women take heart project. Circulation. 2010; 122:130-137.

29. Gutierrez-Grobe Y, Ponciano-Rodríguez G, Ramos MH, Uribe M, Méndez-Sánchez N. Prevalence of non alcoholic fatty liver disease in premenopausal, posmenopausal and polycystic ovary syndrome women. The role of estrogens. Ann Hepatol. 2010; 9(4): 402-9.

30. St George A, Bauman A, Johnston A, Farrell G, Chey T, George J. Effect of a lifestyle intervention in patients with abnormal liverenzymes and metabolic risk factors.J GastroenterolHepatol. 2009 Mar; 24(3):399407.

31. Di Mauro D, Pagano F, Magaudda L, Speciale F, Speranza G, Bonaiuto M, Mallamace A, Trimarchi F.Aerobic exercise and non-alcoholic fatty liver disease: a case report.J Sports Med Phys Fitness. 2009 Dec; 49(4):448-52.

32. Hickman IJ, Jonsson JR, Prins JB, Ash S, Purdie $\mathrm{DM}$, Clouston $\mathrm{AD}$, et al. Modest weight loss and physical activity in overweight patients with chronic liver disease results in sustained improvements in alanine aminotransferase, fasting insulin, and quality of life. Gut. 2004; 53(3): 413-419.

33. Farzanegi P, Pour Amin Z, Habibian M. Changes of Liver Trans-Aminases after a Period of Selected Aerobic Training in Postmenopausal Women.mljgoums. 2014; 8 (1):22-28.

34. Abd El-Kader SM, Al-Jiffri OH, Al-Shreef FM.Liverenzymes and psychological well-being response to aerobic exercise training in patients with chronic hepatitis C. Afr Health Sci. 2014 Jun;14(2):4149.

35. Schwenke DC. Aging, menopause, and free radicals. SeminReprodEndocrinol. 1998; 16(4): 281-308.

36. Hany A. The effect of aerobic athletic program for rehabilitation of hypertensive patients and its effect on physical efficacy and some biological variables. World Journal of Sport Sciences. 2010; 3:197-204.

37. Khorshidi D, Matinhomaee H, Azarbayjani MA, Hossein-nezhad A. Effect of One Period of Aerobic Exercise on Serum Levels of Alkaline Phosphatase and Osteocalcin in Patients with Type 2 Diabetes. The journal of ShahidSadoghi University of Medical Sciences. 2011; 19(5): 676-85. [Persian]

38. Devries MC1, Samjoo IA, Hamadeh MJ, Tarnopolsky MA. Effect of endurance exercise on hepatic lipid content, enzymes, and adiposity in men and women. Obesity (Silver Spring). 2008; 16(10): 2281-8.

39. Bijeh N, Rashidlamir AR, Sadeghynia S, hejazi K. (2013). The effect of eight weeks swimming training on hepatic enzymes and hematological values in young female. International Journal of Basic Sciences \& Applied Research. 2013; 2(1): 17-22.

40. Skenderi KP, Kavouras SA, Anastasiou CA, Yiannakouris N, Matalas AL. Exertional Rhabdomyolysis during a 246-km continuous running race. Med Sci Sports Exerc. 2006; 38(6): 1054-7. 
41. Tartibian B, MoutabSaei N. Effects of 9-weeks high intensity aerobic exercises on parathyroid hormone and marker of metabolism of bone formation in young women. Olympic; 2009; 16(4): 79-88. [Persian]

42. Barzegarzadeh-Zarandi H, Dabidy-Roshan V. Changes in some liver enzymes and blood lipid level following interval and continuous regular aerobic training in old rats. Journal of Shahrekord University of Medical Sciences. 2012; 14(5): 13-23. [Persian]

43. Rodriguez B, Torres DM, Harrison SA. Physical activity: an essential component of lifestyle modification in NAFLD. Nat Rev GastroenterolHepatol. 2012; 9(12): 726-31.

44. Pettersson J, Hindorf U, Persson P, Bengtsson T, Malmqvist U, Werkstrm V, et al. Muscular exercise can cause highly pathological liver function tests in healthy men. Br J ClinPharmacol. 2008; 65(2): 253-9.

45. Bizheh N, EbrahimiAtri A, Jaafari M. The effect of three months aerobic exercise on levels of hSCRP, homocysteine, serum lipids and aerobic power in healthy and inactive middle aged men. Daneshvar(medicine) shahed University/ $19^{\text {th }}$ year;
2012, NO.98: 1-9.

46. Tran, Lokey, 1989. Effects of exercise training on serum lipid and lipoprotein concentrations in women: A meta-analysis. International Journal of Sports Medicine, 424-429.

47.Perseghin G, Bonfanti R, Magni S, Lattuada G, De $\mathrm{Cf}$, Canut $\mathrm{T}$, et al.2006. Insulin resistance and whole body energy homeostasis in obese adolescents with fatty liver disease. Am J PhysiolEndocrinolMetab: 291: E 697-E 703.

48.Cox LK, V. Burke, AR. Morton, et al. The Independent and Combined Effects of 16 Weeks of Vigorous Exercise and Energy Restriction on Body Mass and Composition in Free- living Overweight Men: A Randomized Controlled Trial. Metabolism, 2003 Jan; 52(1): 107-15.

49. Bi WR, Yang CQ, Shi Q, Xu Y, Cao CP, Ling J, Wang XY.Large-scale analysis of factors influencing nonalcoholic fatty liver disease and its relationship with liverenzymes. Genet Mol Res. 2014 Aug 7;13(3):588091. 